\title{
Focus on Creating Teaching in Classroom, Cultivate Innovation Ability
}

\author{
Xiaoping $\mathrm{Hu}^{\mathrm{a}}$, Hong Xie
}

\begin{abstract}
Generative resources are mainly derived from the students (sometimes from the teachers), which is dynamically generated in the students' practice, self-inquiry, and cooperative communication. Gifted children refer to a group of children who have such characteristics as high IQ (intelligence quotient), strong creativity, and good personality. Their intelligence and capability have great potential for further development. As cognitive ability is one of the prominent characteristics of supernormal children, the lecturers can not only pay attention to teaching knowledge (facts teaching), but also need provide proper opportunities for them to develop their aggressiveness, creativities, and challenges when teaching these children. Because students are active in thinking, in the classroom, students often have some unexpected ideas, that is, the generation of the classroom, in the face of this situation, teachers should be how to do? A joke between students in the class, sparked the interest of a classmate, and then under the teachers' guidance, they invented a chemistry experiment instrument $\Omega$ type pipe, illustrated the importance of the teachers focus on creating teaching.
\end{abstract}

\section{Keywords}

Creating teaching, gifted children, $\Omega$ tube

Gifted children refer to children who have high IQ (intelligence quotient), strong creativity, and good personality, featuring active thinking, strong thirst for knowledge and significant interests in exploring the world. They also like to participate, and are good at study. In order to reach their learning potential to the greatest extent, teachers must focus on students' performance in class, to capture the best in their thinking, to provide them with more proper challenging form of education and opportunity for their needs. Therefore, it is very important to stress the concerns of generative thinking in the classroom.

\section{THE STORY OF THE BIRTH OF $\Omega$ TYPE TUBE}

Student J invented a chemical experimental instrument $-\Omega$ type tube, the process of the invention is very interesting, the inventor student $\mathrm{J}$ described the process of the invention:

The invention of $\Omega$ type tube was inspired by the student's joke in the chemical experiment class: One day in November, 2013, in chemistry class, when the teacher was explaining the benefits of electrolysis in a U-shaped tube, suddenly student $Z$ proposed the name $\Omega$ type tube, all the students regarded his idea as a joke. So did the teacher. However, there is a Chinese saying: "The one who talks doesn't mean that, but the listener is serious". All of a sudden, J got the inspiration from his words - "Can we use

aBeijing No. 8 High School, China

\section{Correspondent Author:}

Xiaoping Hu, Xueyuanxiaojie No. 2, Xicheng District, Beijing, China

E-mail: huxp13681552410@qq.com 
$\Omega$ type tube to do the experiment to extract the gas?".

Student J continued to write:

I drew a sketch of the $\Omega$ type tube quickly. To surprise, the drawing was praised by my classmates immediately. They thought that $\Omega$ type tube was very creative, and was obviously better than a U-shaped tube. So I made a further revision of the sketch, and completed the design of the "First Generation $\Omega$ type tube". Soon after, I thought again seriously: What is the real effect of $\Omega$ type tube? Later on, I found that $\Omega$ type tube can be used to replace U-shaped tube, drying tube, gas bottle and Kipps for many chemical experiments in high school. It has the potential of innovation and application.

Chemistry teacher Ms. Xiao-ping $\mathrm{Hu}$ asked us to put inspiration and thinking into text during the winter vacation as homework assignments. So, I completed my paper named "Interesting Invention of $\Omega$ Type Tube".

After our teacher read through the paper, she thought the idea was excellent, and at the same time, she added that I should make some necessary changes to my drawings. She suggested that I increase height of $\Omega$ type tube side columns, in order to prevent the overflow of the liquid, and that I should make a sample tube. I made another revision of the sketch, and drew the specific cut-open view and vertical view, labeled the size and the thickness of the pipe wall, type of the glass and ratio between the various parts, etc. Then I got in touch with a glass instrument plant on the internet, and made a sample $\Omega$ type tube.

Due to lack of experience, I designed tube with only $9 \mathrm{~mm}$ in diameter, so when I received product from the factory, I found the first generation product has the defect of small size: Diameter is too small, both sides of the notch is too short, which made it difficult to do the experiments. So, I revised again, the new version tube is $14 \mathrm{~mm}$ in diameter and I finally had the real product.

\section{STUDENTS ARE ENCOURAGED TO HAVE DIFFERENT THINKING IN THE CLASSROOM}

Question is the starting point of thinking, and asking question is the power of thinking development as well as the entrance to discovery and creation. Many inventions originated from questions in the world, questions are the key to the door of the innovation. In order to encourage students to ask questions in the class, teachers need to take advantage of the characteristics of the gifted children with high IQ and strong creativity, carefully cultivate students to have a strong sense of questioning and exploring, stimulates the desire and interest of the students to think deeply about chemical problems of, drive them to overcome the stereotyped thinking. Finally, students can make use of knowledge to solve the problems under the guidance of the teachers.

If the teachers thought it is intentionally disrupting to ask questions in class and try to stop, maybe a good invention would be killed. Therefore, equality, openness, encouragement, and respects to students' individuality is the necessity for development of students' creative thinking. In such a classroom teaching atmosphere, students can relax, put down the burden spirit and open wings to fly.

Furthermore, students can develop their uniqueness and innovation. It could damage the personality and the creativity of the students, if a teacher tries to overemphasize on his or her authority. Teachers should try to avoid deciding everything by his or her saying in class, try to make the students take part in discussions actively, and strengthen the teaching and learning by two-way communication.

The teachers should have democratic view of coaching and take positive attitude to the challenge of the students; be willing to accept the conflict of the ideas from the students, to create easy atmosphere, teachers should always give affirmative respond to reasonable parts of students' answers, especially those who have their own unique perspective. For novel answers, even if the student's answer is wrong or ridiculous, the teachers also need try to give the affirmation and praise from other aspects, in order to encourage students to present different comments, and explain his points of view bravely.

\section{ENCOURAGE STUDENTS TO PRACTICE BRAVELY}

Gifted children have high IQ, however, our students 
are too young to be persistent. Teachers need to record their good idea as soon as possible, or they are likely to be wiped out.

Gifted children sometimes are not lack of imagination, but are lack of transforming the imagination into reality and are lack of practice spirit. To make sure their ideas are valuable, they need go through practice test, finally the work piece will present its unique features.

$\Omega$ type tube idea seems to be very good, however, the teacher plays an important role in this process, they can coach the students to make the finished product, to do several experiments, and to understand its real value as well as the existing problems.

In the process of the product-making, student $\mathrm{J}$ has gained a lot, such as self-confidence, practical ability, coordinating ability, the ability to communicate with people, eye-brain-hand coordination training, all of which contribute to the creative product and getting ready for the development of his creativity.

Mr. Tao Xingzhi, a Chinese famous educator once said, "Common defects of Chinese education are lack of training students' hands-brain capacity. We separate those skills; therefore, it means nothing at all. Countermeasure of education revolution in China is the alliance of hands and brain. Hands with the power of the brain can do things unbelievable".

\section{ENCOURAGE STUDENTS TO IMPROVE INNOVATION IN PRACTICE}

Innovation is the soul of a nation's progress and is the driving force to realize scientific development. In the development of science and technology, innovation is essential. Innovation, which cannot be reached within one step, must be continuously improved in practice. Student $\mathrm{J}$ has been working for over a year and he is still improving it constantly. Our students are too young to sustain their attention, so the teachers should pay more attention to their work progress and find out the problems and discuss the improvement methods with the students constantly.

$\Omega$ type pipe continues to be improved, J classmate described what he has improved and assumed as follows:

I made some improvements, aiming to overcome shortcomings of the $\Omega$ type tube. Ms. Hu invited me to demonstrate in the class, and we held a discussion to exchange ideas, according to the recommendations as well as the problems discovered in the process of experiment, such as the complex structure, and it is difficult to clean and dry, but easy to be cracked.

I modified $\Omega$ tube into two modular units. I connected two modular units by airway when doing experiments. As a result, $\Omega$ type tube is more convenient to operate and to get clean and dry, not easy to be cracked. Based on this, I designed an inversion $\pi$ type tube, and combined $\Omega$ type tube. This will lead to further expansion of the scope of application, which can take the place of a variety of experimental equipment, and may reduce the purchase cost of the school laboratory, and facilitate more people to use it.

Many problems generate in classroom teaching, how can teachers tackle those problems? It is crucial to take actions and figure out solutions based on subject features, also benefit our teaching targets. If teachers cannot have quick wits in an emergency, it is better to put the question aside for a while until getting good solution or answer. As for students' ideas or opinions, whether they are right or wrong, childish or ridiculous, all are results of their thinking. Teachers should respond in a positive manner, and encourage them to think.

In real teaching situation, the teaching process is specific and uncertain. To show the real learning process and the individual ability of the students, teachers should face starting point of students' cognition carefully. Regarding dynamically generated process, it refers to taking opportunities to grasp the valuable and creative ideas from students in class, and adjusting or changing the preset teaching plan.

In regard of generation in class, not only the incident like " $\Omega$ type tube" but also more and more 
new ideas will generate in the classroom. Sometimes those questions are not to be solved on site; therefore, teachers need to protect children's passion of thinking and good way of discovery, and cultivate such ability of thinking. Furthermore, teachers need to tackle the dialectical relationship between in class and out-of class as well.

\section{CONCLUSIONS}

In the classroom, the students have different answers, the teacher should listen to the response, thinking seriously. The final result is not necessarily consistent with the default, but it must lead to further thinking of the students, otherwise no sense.

In summary, the research has the following conclusions:

(1) Teachers should encourage students to ask questions;

(2) Teachers should respect and think about the views from the students, especially with their own different views;

(3) Teachers should continue to learn, to find the students thinking of the flash point;

(4) Teachers must believe that the students will eventually surpass themselves.

\section{References}

Fu, D. Y. 2010. The Exploration and Utilization of the Curriculum Resources in the Course of Teaching. Retrieved (http://wenku.baidu.com/view/59b20592daef5ef7ba0d3c47. html).

Guo, F. Z. 2011. "Generative Problem Solving Strategy in Classroom.” Scientific \& Technological Information 26:235 Retrieved (http://www.cnki.com.cn/Article/CJFDTotal-KJ XX201126237.htm).

Jia, B. J. 2015. "Design and Application of the Tube for Senior High School Chemistry Experiment." Chinese Journal of Chemical Education 3:78-79.

Song, S. 2010. How to Deal With the Problem of Classroom Generation. Retrieved (http://blog.sina.com.cn/s/blog 62a74bcc0100nd0q.html).

Tao, X. Z. 2008. Education Essays of Tao Xingzhi. Sichuan, China: Sichuan Education Press. Retrieved (http://www. fox2008.cn/Article/2011/20110828072839_65533.html).

Zhang, C. Z. and M. Zang. 2008. "An Analysis of the Generation of Teacher's Classroom Based on Experience." Contemporary Education Teaching 14:7-9.

Zhu, X. B. 2007. "Cognitive Development of Supernormal Children and the Corresponding Educational Strategies." Chinese Journal of Special Education (Monthly) 80:41-45.

\section{Bios}

Xiaoping Hu, BA in chemistry, chemistry teacher, Beijing No. 8 High School, China; research field: chemistry.

Hong Xie, BA in English literature, English teacher, Beijing No. 8 High School, China; research field: English literature. 